\title{
High throughput methods applied in biomaterial development and
}

\section{discovery}

Andrew L. Hook ${ }^{1}$, Daniel G. Anderson ${ }^{2}$, Robert Langer ${ }^{2}$, Paul Williams ${ }^{1}$, Martyn C. Davies ${ }^{1}$, Morgan R. Alexander ${ }^{1}$

${ }^{1}$ Laboratory of Biophysics and Surface Analysis, University of Nottingham, Nottingham, NG7 2RD (UK)

${ }^{2}$ David H. Koch Institute for Integrative Cancer Research, Massachusetts Institute of Technology, 77 Massachusetts Avenue, Cambridge, MA 02139 (USA)

* Corresponding author: Email address: andrew.hook@nottingham.ac.uk

Fax number: +44 1159515110

\section{Abstract}

The high throughput discovery of new materials can be achieved by rapidly screening many different materials synthesised by a combinatorial approach to identify the optimal material that fulfils a particular biomedical application. Here we review the literature in this area and conclude that for polymers, this process is best achieved in a microarray format, which enable thousands of cell-material interactions to be monitored on a single chip. Polymer microarrays can be formed by printing pre-synthesised polymers or by printing monomers onto the chip where on-slide polymerisation is initiated.

The surface properties of the material can be analysed and correlated to the biological performance using high throughput surface analysis, including time-of-flight secondary ion mass spectrometry (ToF-SIMS), Xray photoelectron spectroscopy (XPS) and water contact angle (WCA) measurements. This approach enables the surface properties responsible for the success of a material to be understood, which in turn provides the foundations of future material design. The high throughput discovery of materials using polymer microarrays has been explored for many cell-based applications including the isolation of specific 
cells from heterogeneous populations, the attachment and differentiation of stem cells and the controlled transfection of cells.

Further development of polymerisation techniques and high throughput biological assays amenable to the polymer microarray format will broaden the combinatorial space and biological phenomenon that polymer microarrays can explore, and increase their efficacy. This will, in turn, result in the discovery of optimised polymeric materials for many biomaterial applications.

Keywords: Microarray; Biomaterials discovery; High throughput; Surface analysis; Polymerisation

\section{Contents}

1. Introduction 2

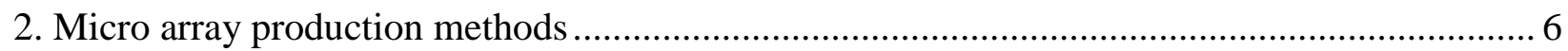

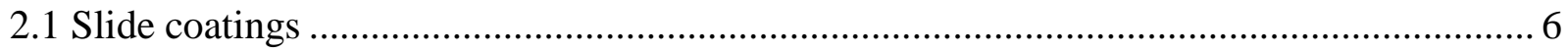

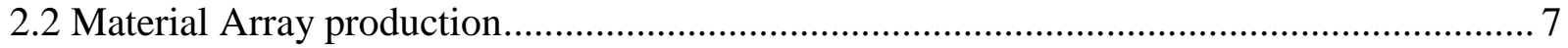

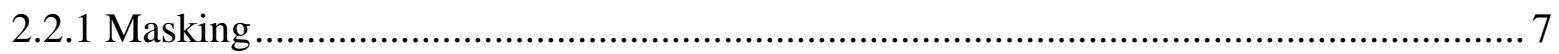

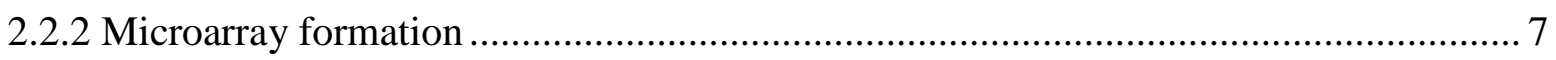

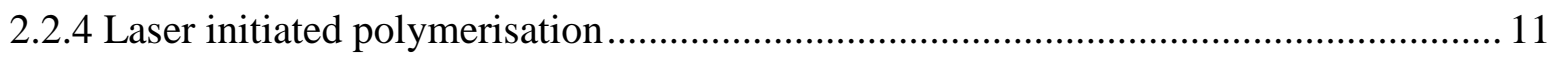

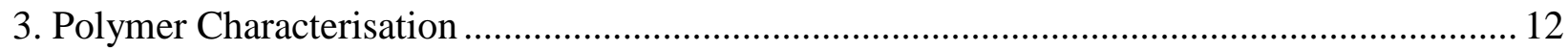

4. Assessment of Biological Response to micro arrays ....................................................... 14

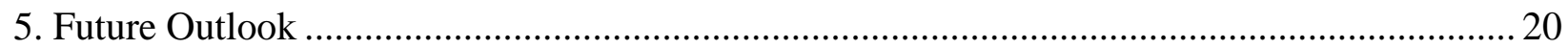

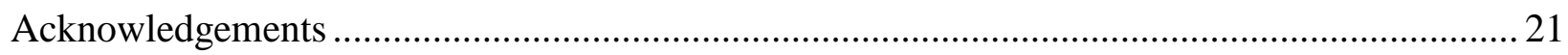

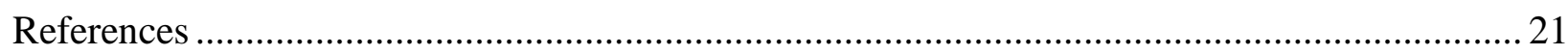

\section{Introduction}

Combinatorial chemistry methodologies, initially developed and applied in the pharmaceutics industry for the discovery of drugs, involve the synthesis, processing and screening of vast numbers of molecules in parallel [1, 2]. To be useful, combinatorial methodologies require complementary high throughput 
characterisation approaches, to both define the chemical or material structure and 'screen' the performance in the desired application [3]. Thus, a large amount of effort has gone into bulk, surface and biological characterisation using approaches compatible with the high throughput philosophy [4]. Such an approach is of particular interest when there is no theoretical basis for predicting performance from the structure/composition of a molecule, formulation, or material. This is often the situation when considering the application of synthetic compounds in biological environments, where the target receptor or underlying biological response remains either poorly or only partly understood. This is particularly true of the field of biomaterials where to date there has been little progress in developing a theory relating the surface chemistry of materials to the biological response e.g. in the control of stem cell differentiation or maintenance of their pluripotency for therapeutic application through material-biological interactions.

Early approaches for the combinatorial production of large numbers of different compounds utilised solid-phase peptide synthesis methods, whereupon short peptides were grown from solid resin supports, usually in the form of beads, in a stepwise manner [2]. A library of molecules was produced by sequentially splitting the beads into aliquots that were each coupled with a different monomer, then the beads were recombined, mixed and again split to repeat this process [2]. This method has also been used for producing short oligonucleotides [2], and more recently, with the advent of microwave induced solid-phase synthesis, has been used to produce non-linear organic molecules [5].

These combinatorial molecular synthesis approaches have been extended to the development of materials by using combinatorial approaches specific to the production of solids [6]. An early example was the synthesis of a library of minerals as thin films on a single 'chip' using a sequential masking and unmasking procedure with ion sputtering to produce a range of material compositions [7]. Subsequently, many variations on this theme of combining components to create a range of material types and/or compositions have been published including photoluminescent composite materials [8], polymer films [9], conductive polymers for the creation of electronic circuitry components [10,11], metal salt catalysts [12], transition metal catalysts [13], metal nanoparticles [14, 15], ceramics [16-18] and organic light emitting diodes [19]. Polymeric materials are of particular interest for investigation by high throughput strategies, both because of 
their wide application in bio-medicine and because of the large combinatorial space associated with the large number of monomers available and their possible combinations [20]. One methodology used for the parallel investigation of multiple polymer samples is spatial gradients [21-25]. Gradient investigations employ the variation of the relative composition of two material properties by producing a sample that varies gradually, e.g. in chemical composition [26] or topography [27], across a convenient distance. Between the two compositional/morphological extremes, the response of the property of interest, e.g. cellular adhesion, to the changing composition of the gradient as a function of position can be compared on one sample [28]. This achieves significant time saving when compared with looking at many individual samples, each with a uniform but different composition, and reduces inter-sample biological variance. Two-dimensional gradients have also been reported, whereupon orthogonal to one gradient a second gradient is introduced. As such, every position on the gradient presents a unique combination of the two properties [27]. This gradient methodology is well suited to high throughput optimisation of a particular material property where a limited number of chemical components or properties are involved. However, due to the restrictions on the number of components that can be incorporated onto a single gradient, the gradient approach is limited in the discovery of new polymers and is more appropriate for optimisation. The gradient approach may be more appropriate as a discovery tool for non polymer materials, e.g. ceramics, glasses and metals, where new materials are created with very different properties at different stoichiometric compositions.

The high throughput discovery of new polymers is better suited to the microarray sample format [29]. The high throughput discovery of materials (HTDM) is defined here as a methodology that allows new materials to be found utilising a large library of materials through screening for a particular performance in an application of interest. Microarrays, which can comprise of thousands of spots on a single glass slide at addressable locations, have been extensively used for genomics by presenting DNA or protein based probe molecules [30-32]. Replacing biomolecules with monomers allows the formation of a combinatorial library of polymer spots. Importantly, individual polymers are spatially resolved, which enables the high throughput, cost effective and parallel screening of every member of large libraries of polymers to identify new materials with interesting properties. 
Microarrays can be formed using a variety of different techniques including photolithography, softlithography, microfluidics, nanolithography, contact printing and ink-jet printing [33, 34]. Of these approaches, the best suited for the production of vast arrays of varied materials are the direct writing methods, where a print head comprising a nozzle or tip to spatially deliver molecules or using a beam of photons or high energy particles to initiate synthesis is used rather than the masking approach described previously for sputtering of materials. Of the direct writing methods, contact and ink-jet printing have almost exclusively been utilised for formation of polymer microarrays due to their ability to produce patterns of thousands of different materials at a feature size around $100 \mu \mathrm{m}$ in a rapid manner. Furthermore, these approaches are readily amenable to changes in the printing pattern, which cannot be achieved where a master pattern is designed, for example in microcontact printing.

The microarray format also provides an ideal platform for the rapid assessment of material-cell interactions, which are intrinsic to all biomaterial applications, by presenting many materials in a manner amenable to cell culture. By appropriate choice of bioassay, the material presenting the optimised performance can be readily selected. The absence of adequate polymeric materials for biomedical application and, thus, the motivation for materials discovery, is well illustrated by the prevalence of surface modification of polymers in an attempt to achieve the required surface properties [35-47]. The creation of a diverse range of polymeric materials is an important requirement for producing biomaterials ideally suited to the unique and specific requirements of every medical application [20]. This review focuses in particular on the fabrication and physio/chemical characterisation of polymer microarrays and their biological evaluation, since we believe that this adaption of high throughput screening will yield the maximum benefit from the process. This will put these methods in the context of their use in the discovery of new polymeric biomaterials. 


\section{Microarray production methods}

\subsection{Slide coatings}

For platforms used for HTMD, the chemistry of the underlying substrate material plays an important role in the formation of the array as well as the success of subsequent bioassays. Material arrays used for the discovery of biomaterials require a substrate that is both adherent to the materials printed on it and is resistant to the attachment of biomolecules and living cells in order to optimise the signal to noise ratio of any biological assay and prevent cross-talk from one spot to another. A number of different surface coatings have been developed with these needs in mind, with emphasis generally placed on using cheap and robust coating methodologies. One such example is the dip-coating of a commercially available epoxide functionalised slide into a poly(hydroxyethyl methacrylate) (pHEMA) solution [48, 49]. Dip-coating is a simple technique that can easily be achieved in any laboratory, making this modification approach accessible. pHEMA is an attractive coating as it is able to resist cell attachment as well as providing a matrix into which printed material can penetrate and physically entangle to improve the stability of the spots [48]. Agarose is an alternative coating that may be applied by dip coating using commercial aminoalkylsilanated slides [50]. Agarose and pHEMA are intended to prevent cell attachment whilst being non-toxic. Poly(ethylene glycol) (PEG) based coatings have also been widely used for producing low-fouling coatings, and are widely used to effectively inhibit biomolecular adsorption [51]. In order to produce a PEG modified surface, a methodology has been proposed by the groups of Griesser, Thissen and Voelcker in which a PEG layer is reacted with an amine plasma polymer coated slide. [51-54]. Of importance was the production of a dense, brush-like layer, produced by grafting the PEG to the surface at 'cloud point' conditions in order to optimise the ability of this layer to resist the adsorption of biomolecules. Polymers arrayed onto this surface can be covalently attached by modifying the polymer with a cross-linker or incorporating epoxy groups into the PEG layer. This is discussed further in section 2.2.2 Microarray formation. 


\subsection{Material array production}

The creation of material arrays requires a combinatorial library of materials to be generated and positioned at addressable locations on a substrate surface. The library can be generated prior to the synthesis of the array, for example by printing pre-synthesised polymers, or concomitant with the formation of the array, for example by printing monomers that are polymerised on-slide. Once the material has been deposited onto the substrate it needs to be fixed with sufficient strength and durability that it can resist the biological evaluation process, which is a challenging requirement since it typically involves submersion in water. This may be achieved by physical entanglement, non-covalent or covalent interactions. The key advances in polymer microarray production are highlighted in Table 1.

\subsubsection{Masking}

Initial methods to produce a microarray of solid materials on a single substrate used a sequential masking procedure, inspired by methodologies developed for combinatorial chemistry [7]. In this approach, illustrated in Figure 1, masks were used to ensure that certain regions were coated by a particular material, for example by sputtering a ceramic material, whereas other regions remained uncoated. The mask was then exchanged, moved or rotated such that a different pattern of exposed and unexposed regions was revealed. A new material could then be deposited. By repeating this process a number of times, each time with a varied mask and material, many different combinations of materials at unique positions on the substrate were generated (Figure 1). Using seven different sputtering targets combined at various ratios, an array of 128 unique materials was produced [7]. This approach was improved by using the stepwise generation of photomasks [2], which provided a more precise masking of the surface by eliminating the diffusion of sputtered material underneath the mask. However, this process is limited in the materials it can be used for and is not amenable to variations in pattern design, due to the requirement of a mask.

\subsubsection{Microarray formation}

Polymer microarrays are typically formed by either contact or ink-jet printing. Contact printing involves the use of a robot moving a metallic pin, which is dipped into a solution and then spotted onto the substrate 
surface by making contact, as illustrated in Figure 2. The pin may either be solid or contain a groove analogous to an ink quill, such that the solution is drawn up into the pin and the spotted material is taken from this reservoir (Figure 2). The ink quill design has the advantage that more spots can be printed from a single dip in the solution. Contact printing is attractive for ease of transfer and the absence of small apertures in the system that can become blocked. The size and shape of the pin used is the determining factor in the resultant spot size. Contact printing was first used to produce an acrylate microarray on a pHEMA coated slide by Anderson et al. using on-slide UV photo initiated polymerisation, as illustrated in Figure 3a [48]. This was achieved in four steps; arraying acrylate monomers with an initiator, activation of initiator upon UV irradiation, polymerisation of the monomer, and finally removal of the solvent. This resulted in stable, covalently crosslinked polymer spots. By premixing the various monomers at a set ratio a large polymer library of 576 materials was readily achieved in triplicate on each slide. A typical array formed by this method is shown as Figure $3 \mathrm{~b}$. This array was printed on a pHEMA background to avoid cell attachment to unmodified regions. The attachment and pluoiptoency of embryonic stem (ES) cells was rapidly screened with many disparate chemistries on this array $[48,55]$. A similar approach has also been developed on a PEG background [56]. Here, an array of seven different materials was constructed by depositing spots of monomer solution with initiator. The spots were polymerised by UV exposure and subsequently used to assess the attachment of HeLa cells. This approach decreases the time required for polymer library synthesis and microarray formation by combining these processes. Furthermore, this approach allows materials that cannot be printed, such as cross linked polymers, to be included in the polymer library as they are printed in the monomer state. However, the polymer synthesis conditions are likely to differ when materials are produced on a larger scale.

Subsequently a biodegradable polyester microarray was deposited on a pHEMA coated slide from a presynthesised library by Anderson et al. [49] and shortly afterwards a similar approach was taken for depositing polyurethanes on an agarose gel coated slide by Tourniaire et al. [50]. In these approaches polymers were pre-synthesised and deposited from solution, which allowed standard polymer characterisation techniques such as gel permeation chromatography and differential scanning calorimetry to 
be utilsied. An alternative to contact-printing is ink-jet printing. In this approach a nozzle is used to draw up then eject polymer solution onto the substrate at a defined droplet volume, as depicted in Figure 2 . The volume of the droplet and the surface energy of the substrate material and the printed solution determine the resulting spot size. This technique enables the precise control of the amount of material deposited and avoids contact with the surface. However, solutions of different viscosities and surface energies cannot easily be printed under similar conditions, limiting the number of different materials that can be included in a single printing run. In addition, the small orifices are susceptible to blockage by dust particles or aggregates of material [9]. This method can be cost-effective and readily accessible to most laboratories by using modified, commercially available ink-jet printers [57].

Ink-jet printing was first used to prepare a polymer array from individually deposited monomer for water soluble acrylamide monomers to form hydrogels [58]. Three monomers were deposited sequentially onto the same position, with a solution containing a catalyst to initiate the reaction being printed subsequently. This drop in drop mixing approach required that the solvent, water in this case, did not evaporate before the mixing was complete. The authors proposed that the turbulence induced by the printing procedure resulted in the complete mixing of the monomers within the drops after 1.5 mins. This approach was used to create an array comprising thirty-six different materials from six monomers. Similar to the on-chip polymerisation process previously described, the synthesis of a combinatorial library of polymers was successfully coupled with the production of a polymer microarray. This not only saves time by removing the need to pre-mix monomer solutions, but also greatly increases the range of combinations that can be achieved. However, the successful on-slide mixing of monomers must be carefully assessed as is likely to be different for each monomer, polymerisation and printing system employed.

One possible limitation to ink-jet printing is the rapid loss of solvent from printed picolitre-sized droplets. The dynamics of the evaporation of droplets can play a determining factor on the morphology of arrayed spots [59] and can result in the uneven distribution of deposited molecules, the common example being the 'coffee rim effect' due to the solute diffusion towards the pinned rim of the spots [60]. This can be controlled, to some extent, by selecting an appropriate solvent volatility and by controlling environmental 
conditions such as humidity and temperature. However, there are some monomers and solvents that cannot successfully be printed. An ingenious method for ink-jet printing was reported in order to limit solvent evaporation, hence broaden the monomers that can be printed, which employs a thin layer of paraffin oil to reduce evaporation. Monomers dissolved in 1-methyl-2-pyrrolidinone were printed through this oil layer, where they sank and settled on the substrate where they could subsequently be polymerised [61]. Water droplets could also be printed through the oil layer, and analysis of these droplets suggested that disappearance of the droplets was prevented for more than four hours. Here, relatively large droplets resulting in large spots sizes $(0.62 \mathrm{~mm})$ were used. Extensive washing was required after polymerisation to remove the oil. The resulting arrays were used to screen for mouse ES cell attachment. Potential contamination of the surface by the oil with the polymerised spots, and dissolution of monomer into the oil layer are important issues that remain to be addressed in this approach.

Polymer deposition from solution and on-slide polymerisation relies on non-covalent interactions, such as physical entanglement, to ensure the polymer microarray is stable throughout subsequent bioassays. Thus, alternative approaches, such as grafting-to, have been investigated whereby the arrayed polymers are covalently linked to the surface, ensuring greater stability and durability of the resultant spots. This can be accomplished by functionalising the polymers being arrayed with a reactive functional group that, upon activation, covalently links the molecule to the surface. For example, amine functional polymers of interest were functionalised with a bi-functional linker containing both a $N$-hydroxysuccinimide activated ester and a phenyl azide group [62]. UV irradiation of the phenyl azide group formed a radical that would readily form a covalent linkage by inserting into the $\mathrm{C}-\mathrm{H}$ bond, making this method applicable to any organic coating [62]. However, this process cannot be applied to chemically inert materials and, furthermore, the presence of the linker may conflict with desired properties of the material in use. To overcome this limitation it is desirable to covalently link the polymer to the surface without having to modify the polymer itself. This can be achieved by functionalising the substrate with a group that covalently links with arrayed polymer. For example, a grafting-to approach was accomplished by producing a multifunctional coating with both PEG groups, that provided a low-fouling background, and epoxy groups, that enabled subsequently spotted 
biomolecules, synthetic and natural polymers to be covalently linked to the surface in a suitable manner for subsequent cell attachment assays using HeLa cells [53]. This is advantageous because the structure of the arrayed material is unaltered; however, the substrate chemistry becomes limited. In this particular study a plasma polymer slide coating approach was used, which is advantageous as it can be applied to almost any base substrate.

\subsubsection{Laser initiated polymerisation}

A laser based method has been reported for forming polymer spots that avoids the evaporation of the printing solution and does not rely on the surface energy of the substrate surface and arrayed solution or droplet evaporation as the determining factor in the size of arrayed features. In this technique, localised polymeric structures were formed using laser initiated polymerisation. The area of the focussed laser was the determining factor for causing site specific polymerisation and, thus, spot size. A microfluidic setup was constructed that enabled a monomer solution containing an initiator to be flowed through a chamber on a chip surface. An $\mathrm{X}, \mathrm{Y}$ and $\mathrm{Z}$ stage moved the substrate under a $\mathrm{CO}_{2}$ infrared laser that delivered a pulse into the monomer solution, heating a localised region of the monomer solution and initiating polymerisation. Removal of the laser resulted in the termination of polymerisation. A typical experimental setup used for this procedure is shown schematically in Figure 4. In this manner localised polymeric structures could be grown off the substrate surface, with the possibility of producing three-dimensional structures. Replacement of the monomer solution with a different monomer could be used to produce a heterogeneous array of polymeric structures [63]. An array of 14 different polymers spots with an average diameter of $300 \mu \mathrm{m}$ were produced, although spot sizes as small as $70 \mu \mathrm{m}$ were reported. Cross-contamination from one monomer solution to the next was not investigated. In this case, the polymerisation occurred in the presence of dansylL-phenylalanine as a template molecule, which was eluted subsequent to polymerisation. This approach enabled the identification of the most suitable polymer to produce an effective molecular imprint of the template molecule, which was subsequently used to selectively detect the template molecule from a mixture of enantiomers and derivatives, such as dansyl-D-phenylalanine [63]. 


\section{Polymer characterisation}

Polymer microarrays provide exciting opportunities for the HTDM. However, the surface of a polymer is often different from its bulk, as with many materials, for reasons of surface energetics. Copolymers, required for formation of a combinatorial library, are further susceptible to differences between the surface properties and the raw ingredients included in the solution due to surface segregation of components and phase separation. Thus, particularly when wishing to understand the influence that material properties have on biological systems, it is important to conduct comprehensive surface characterisation of the microarrays produced. Such analysis, in addition to the screening process, enables the elucidation of the relationship between surface chemistry and a biological phenomenon of interest, identifying not only which material is suitable for an application but also for what physico-chemical property is responsible for its good performance. It is hoped that this will help in elucidating the principles governing cell and protein adsorption to surfaces. This is an important development for the field of microarrays and can be seen as the difference between a high throughput screen of a property, where the mechanism for the performance is not necessary to the process, and the development of a structure-property relationship which can form the basis of the design of future materials. A combinatorial library including diverse constituents is particularly amenable to this process.

Imaging approaches, such as optical and electron microscopy, can be used to image the size and shape as an initial, rapid assessment of the integrity of entire polymer microarrays. For more detailed analysis, Davies, Alexander et al. have developed a procedure utilising a suite of surface specific techniques, termed high throughput surface analysis (HT-SA), to allow comprehensive surface chemical analysis of polymer microarrays using X-ray photoelectron spectroscopy (XPS), time-of-flight secondary ion mass spectrometry (ToF-SIMS) and wettability analysis from sessile water contact angle measurements [64]. A schematic representation of the various techniques and a summary of the information gained from each technique is summarised in Figure 5. The high throughput nature of this analysis is imperative when considering the combinatorial nature of the arrays being studied [3]. XPS allows the quantitative measurement of the elemental composition of the top $10 \mathrm{~nm}$ of the substrate surface. This is achieved by bombarding the surface 
with X-rays and measuring the number and kinetic energy of ejected electrons, which is proportional to the number of atoms and indicative of the element it originated from respectively. The chemical state of each element can be quantitatively determined by high-resolution measurements. ToF-SIMS provides a mass spectral measurement of the top monolayer of the solid surface, however, it is not readily quantified and, thus, is used as a complementary surface analysis technique with XPS [65]. ToF-SIMS is achieved by sputtering the surface with a beam of primary ions and measuring the mass of secondary ions ejected from the top uppermost surface. The chemical information produced is vast and, therefore, requires multivariate statistical methods to identify correlations that are not obvious and cannot readily be noticed from inspecting the raw spectra. Of significance is the use of partial least square (PLS) regression to correlate particular material properties with chemical or biological phenomenom [66]. PLS is a multivariate regression technique that correlates a dependant variable with an independent variable that contains multiple components, such as spectral data from ToF-SIMS. This approach has been used to compare wettability, cell attachment and protein adsorption with surface chemistry, with clear trends being discovered that enable properties such as wettability to be predicted from the material's chemical structure [66-68].

The measurement of wettability, achieved by sessile water contact angle measurements, is a nondestructive surface analysis methodology that can be conducted at ambient conditions; both XPS and ToFSIMS require ultra high vacuum conditions. Typically, water contact angle measurements use droplets with a volume greater than $1 \mu \mathrm{L}$ and a sampling area of a few square millimetres. Such an approach is not amenable to small polymer spots of diameters approximately $300 \mu \mathrm{m}$ and is difficult to adapt to the high throughput methodology. Water contact measurements of libraries of polymers have been achieved by producing large scale polymer films, however, such an approach presents significant time restraints when trying to analyse polymer libraries comprising hundreds of constituents. To overcome these limitations, the use of picolitre sized water droplets has recently been reported, and offers an approach to sample the wettability of polymer spots in an array format in a high throughput manner [59].

Although the biomolecules of biological systems interact with only the surface of non porous materials, the bulk properties of the material can also play a significant role, for example, mechanical properties can be 
important for the success of a material in an orthopaedic application and varied material elasticity has been shown to alter the differentiation fate of stem cells [69]. As such, methods that allow material's bulk properties to be screened in a high-throughput manner are of interest.

Infrared and Raman microspectroscopy provides an approach to measure the bulk chemistry of materials in a spatially resolved manner $[70,71]$. Moreover, spectra from a single sample can be acquired in a few seconds. Thus, this technique is well suited to the high throughput approach and could be of use for characterising the bulk chemistry of polymer microarrays. Of particular interest would be the comparison of bulk and surface chemical data. This technique has previously been used to characterise combinatorial polymer libraries [6] and should readily be adaptable to the polymer microarray format.

In order to measure the mechanical properties of a library of polymers in array format nanoindentation has been investigated. In this approach, a diamond indenter of known dimensions is pushed into a material leaving an indent. The depth of penetration, up to a user-specified load, is monitored and can be used to determine a material's elastic modulus and hardness. This was used to study a library of 1700 polymers, which was synthesised and analysed by nanoindentation within a few days as a demonstration of the high throughput capabilities of this approach [72].

\section{Assessment of biological response to microarrays}

In order to move from a combinatorial library of polymers to biomaterials discovery, the biological response on each polymer member must be assessed. Initial work by Kohn et al., demonstrated this possibility. In one such study, 42 distinct polymers, derived from 6 diphenol monomers and 7 diacid monomers, were used to study fibroblast proliferation. Increased proliferation was observed for decreased contact angle over the range of $65^{\circ}-100^{\circ}$ [47]. However, this approach required each polymer to be coated onto a separate glass substrate, restricting the high throughput biological assessment. The development of the polymer microarray format heralded the realisation of high throughput biomaterials discovery. A key advantage of polymer microarrays is the ability to expose an entire polymer library to a bioassay in parallel, thus, avoiding inter-sample biological variation and permitting cost-effective analysis. This has enabled 
revealing studies into the attachment of cells onto varied materials, and importantly, enabled material-cell interactions to be explored on materials that conventional studies would not have permitted due to time restrictions. In order to maximise the benefits that a high throughput platform provides, the biological response must also be assessed in a high throughput manner [3]. The use of fluorochromes has been widely used for the high throughput characterisation of DNA and protein microarrays [73] and can be used to detect quantitatively fluorescently labelled biomolecules on every polymer spot. This is achieved by the use of a laser scanner, which is able to acquire fluorescence signals across an entire array at a resolution of approximately $5 \mu \mathrm{m}$ within a few minutes. Typically, target molecules are associated with a fluorescent tag molecule and incubated with the substrate, or alternatively particular biomolecules within an attached cell can be fluorescently stained or expressed with a fluorochrome by transfecting the cell with the appropriate gene. This enables enquiries into the total protein adsorption or cell attachment on a polymer microarray to be answered successfully, for example, identifying optimal materials for fibronectin (Fn) adsorption [55]. For such analysis any autofluorescence of the polymeric materials must be carefully considered, and for total cell attachment the fluorescence signal must be calibrated by manually counting cells using optical microscopy aided by fluorescent labelling, e.g. DNA/nucleus with SYTO 24. However, investigations into greater biological complexities than the total proteins or cell number are met with acquisition and processing limitations in order for the answer to be obtained in a high throughput manner. For example, it is more difficult to use polymer microarrays to detect subcellular changes in cells due to the material-cell interaction such as a rearrangement in actin filaments because techniques restrict the feasibility of acquiring and processing in a high throughput manner high resolution images of every cell across an entire array. These limitations can be met with improved computational power, the automation of experimental processing or by the creation of innovative approaches to experimental design. One important innovation for the high throughput, subcellular analysis of cells is the use of automated microscopy systems. This offers optical diffraction limit resolutions of approximately $500 \mathrm{~nm}$ to be achieved, enabling subcellular features to be visualised. The automation also enables images of individual cells to be captured across entire arrays of hundreds of polymers. Furthermore, these microscopes often include multiple fluorescence channels such 
that multiple fluorochromes used to stain specific regions of cells can be captured in a rapid fashion [48, 50, 74]. Representative images of human ES cells growing on a polymer microarray with multiple channels are shown in Figure 6. In order to process the many hundreds of images that can be acquired by these methods whilst still maintaining a high throughput approach, computational qualification of image features must be realised. This has been achieved by acquiring images of transfected cells expressing a specific protein of known function with a green fluorescing protein (GFP) and assigning the fluorescence pattern to the known subcellular location of the protein. The subcellular position of expressed GFP-tagged proteins of unknown subcellular position could then be detected and assigned by reference to the set of assigned images [69]. This technique was used to identify proteins localised to the nucleus, peroxisomes, lamina, nucleoli and the plasma membrane with greater than $80 \%$ accuracy.

An alternative to fluorescence reading in the use of surface plasmon resonance, whereupon the adsorption of biomolecules to a surface is measured by observing changes in the intensity of a light source that excites surface plasmons at a gold surface [75]. This method is label free, in situ, surface sensitive, measures in realtime and, by measuring the light source with a microscope or camera, spatially resolved measurements can be made using a method termed surface plasmon resonance imaging [76-78]. This approach has been applied to the study of protein-material interactions on a microarray format [79]. Such studies are important as cell-material interactions are often governed by material-protein interactions. In this method, an array of polymers was simultaneously studied for its interactions with injected proteins, with the ability to extract kinetic and thermodynamic data. Furthermore, this approach can also be used to characterise the thickness and swelling of the polymer spots $[79,80]$.

Biological assays conducted on polymer microarrays for the discovery of new biomaterials are predominantly cell-based assays. Initially, studies using polyacrylate microarrays focussed on the behaviour of human stem cells on polymers [48, 49]. Stem cells have the potential to differentiate into many tissue types. Materials that effectively and predictably control the behaviour of these cells would be of great interest for cell therapy and regenerative medicine, and the vast number of material properties to be explored in order to achieve this makes these interactions of particular applicability to the high throughput 
methodology [81]. For analysis on a polymer microarray, stem cells were prepared by culturing to form embryoid bodies for six days before seeding onto the microarray. The cells were grown for a further six days with retinoic acid and serum before differentiation was screened for by staining cytokeratin 7 , an intermediate filament protein found in many glandular and epithelia. This approach identified many materials that insitigated differentiation into cytokeratin positive cells, identifying a potential methodology for preparing pure populations of epithelia-like cells [48]. The chemical composition of these materials could be used as leads for the subsequent development of materials that instigate an epithelial fate for ES cells. An image of cells attached to the polymer microarray, with cells stained positive for cytokeratin shown in green, is shown in Figure 6. The large number of cells requiring analysis seen in this figure highlights the processing difficulties faced when working with microarrays.

Additional cell-material based studies have implemented presynthesised polyurethane microarrays to screen for new biomaterials that support the attachment of human renal tubular epithelial cells. Polyurethanes are of interest due to their unique mechanical properties and biocompatibility. After culturing cells on the array for five days, polymers spots containing the monomers of 4,4'methylenebis(phenylisocyanate) or poly(tetramethylene oxide) diol were identified as supporting more cell's relative to the other polymers studied [50]. This system has also been used to study the attachment of L929 fibroblast cells [82]. These cells are of interest due to their function within the structural framework of many tissues and their critically role in wound healing. Comparison between the wettability of the materials used with cell attachment identified a preference of the cells for more hydrophobic surfaces [82]. A polymer array consisting of 210 presynthesised polyurethanes and 58 polyacrylates was further used to study the cellular adhesion and proliferation of K562 suspension cells, that are not anchorage dependant [83]. An automated microscopy system was used to detect and count the number of cells growing on each polymer spot. This identified a number of polymers that promoted the attachment of K562 cells. In particular, amine containing polymers were found to produce strong cellular adhesion. Subsequent analysis of cell transcription revealed that adhesion was coupled with a downregulation of membrane receptors, ligands and channels [83]. Polymer arrays have also been used to screen for materials that support the attachment of HeLa cells [56], 
bone marrow dendritic cells [84], chondrocytes and neural stem cells [49]. One important application derived from discovering materials that selectively bind specific cells is the ability to sort heterogeneous populations of cells, which is relevant for isolating specific cell lines from primary sources. This was demonstrated with osteoprogenic cells, whereupon polymer microarrays were used to identify a material from a library of polyurethanes that could exclusively bind STRO-1+ cells, derived from a human bone marrow mononuclear cell population. This material was used to isolate these cells from other immature osteoblasts like MG-63 cells, STRO-1+ human fetal skeletal cells and differentiated osteoblast-like SoOs cells, demonstrating the selectivity of the identified material [85].

In order to underpin cell attachment assays on polymer microarrays with an increased knowledge of the underlying mechanisms, the investigation of protein adsorption is of interest as it is well known that protein adsorption plays a key role for cell attachment to materials [86]. For this purpose, fluorescently labelled human Fn has been widely studied due to its role in the ECM and its cell adhesive properties. In a study on a polymer microarray the total amount of adsorbed protein was measured by a fluorescence scanner whilst the adhesive force between the polymer spots and Fn was also measured by probe microscopy force measurements [87]. Importantly, both these analysis methods are amenable to the high throughput approach. A strong correlation between the measured adhesive force and the amount of protein adsorbed on each polymer spot was observed [87]. It was found that protein adsorption could be controlled by altering the constituents of the polymer mixtures, and generally speaking, polymers that supported high Fn adsorption also supported high cell attachment when arrays were pre-coated with Fn [55]. A typical map depicting this result is shown in Figure 7. This result identified the ability of trimethylolpropane benzoate diacrylate (monomer 14), a triacrylate that forms a cross-linked polymeric network, to support both protein adsorption and cellular attachment. When looking at specific monomers, a sigmoidal relationship was identified between Fn adsorption and cell attachment. However, there were apparent disparities observed between cell attachment and Fn adsorption. For example, neopentyl glycol diacrylate (monomer 8) showed high levels of cell attachment but only minimal amounts of Fn adsorption. This may be caused by the induction of different conformational orientations of Fn on different surfaces, resulting in the high adsorption but low 
activity of Fn on some polymers and low adsorption but high activity on other polymers. This highlights the complex nature of these interactions and the need for HTSA to elucidate underlying mechanisms. Significantly, the use of a microarray enabled the correlation of material chemistry with biological events such as cell attachment and protein adsorption [55]. This marks an innovation in microarray technology, whereby the microarray is not simply used to identify positive or negative 'hits' in a screening manner, but additionally can be used to determine the underlying material-biological interactions in order to predict the behaviour of a new material in certain biological conditions.

Cell attachment can also be studied by printing a polymer microarray containing naturally occurring polymers and other ECM components onto a polyacrylamide gel. Such an approach was used for the high throughput study of primary rat hepatocyte and I1 14 mouse ES cell interactions with varied combinations of five different ECM components to create a total of 32 unique combinations [88]. In this case maintaining hepatocyte function and differentiating embryonic cells to an early hepatic fate was of interest. The results showed that two ECM components could together produce an effect that they would do the opposite of when displayed separately [88]. For example, Fn and collagen III individually induced a negative effect on hepatocyte function compared to the average response to other ECM components present on the array, however, when combined with collagen I a positive effect on hepatocyte function was observed. This study also identified collagen I and Fn as being the two ECM components best able to instigate the differentiation of ES cells to an early hepatic fate. Furthermore, this report demonstrated the possibility of screening ES cells with a microarray to produce materials that trigger differentiation pathways in a controlled manner, although only one pathway was screened for in the present study.

Polymer microarrays have also been used to alter phenotypes of living cells upon the over-expression or silencing of specific genes of interest using transfected cell microarrays (TCMs). These microarrays are formed by seeding cells onto a surface with arrayed DNA. Transfection occurs when adhered cells uptake and express DNA from the surface $[89,90]$. Transfected cell microarrays are important for being able to study genomics in a high-throughput manner within living cells, where all the cellular machinery is present for post-transcriptional modifications. Polymer microarrays can assist the use of TCMs by directing cell 
attachment exclusively to regions where DNA has been arrayed [62]. The array consisted of plasmids encoding for either a GFP or a red fluorescing protein (RFP) in a checkerboard pattern. Furthermore, studies have shown that the underlying polymeric material plays an important role in the delivery of the DNA to the cells [91], thus, by performing this on a polymer microarray many different surface chemistries could be screened simultaneously to find the surface which best facilitates this process. The efficiency of cellular transfection for various cell lines (human embryonic kidney cells, human cervical adenocarcinoma HeLa and mouse melanoma B16F10) was screened on a polyacrylate microarray. A number of co-polymers that achieved high transfection efficiency for each cell line were identified, with a high content of methylmethacrylate found to be a common feature [92]. This approach may be of particular use with cell lines that are typically difficult to transfect.

\section{Future outlook}

The application of combinatorial approaches to the discovery of new biomaterials provides exciting opportunities to produce materials designed to give optimal performance for specific applications. This process has been facilitated by the development of the automated fabrication and analysis of polymer microarrays, produced largely by contact or ink-jet printing. Studies thus far have focused on the discovery of materials that support cell attachment for particular cell types. This approach may be of interest for identifying materials that promote the attachment of a specific cell type and possibly for sorting heterogeneous populations of cells. Other studies have focussed on controlling adhesion and maintaining the pluripotency of stem cells. Future studies will focus on supporting the growth and controlling the differentiation of stem cells, due to the enormous therapeutic benefits that stem cells offer. However, there is a broad range of biological-material interactions that can be explored, the limiting factor being the ability to conduct a biological assay and assess the corresponding response in high throughput. Innovative solutions to these limitations will result in a broadening of the biological questions answerable by microarrays and progress towards ambitious applications such as stimulated neurogenic repair and the creation of functional organs from stem cells, both of which include a biological-material interaction. 
In addition to applications of microarrays in screening for desirable material properties, the size of the sample set provides enormous potential to be able to elucidate key underlying principles that govern biological-material interactions. This can be achieved by correlating material properties with biological events, such as cell attachment. This, in turn, enables the behaviour of new materials to be predicted under certain biological conditions and, consequently enables the rational design of subsequent material arrays. Such an approach requires high throughput methods that are able to analyse the surface properties of the polymer microarrays and multivariate statistical analysis that identify correlations that are not immediately obvious. This is an emerging use of material microarrays that has potential to facilitate biomaterials discovery, and we believe this to be an area of future growth [93].

A key challenge in the application of microarrays is the effective processing of the vast amounts of chemical and biological data that can readily be produced. Innovations and automation in the computational processing and experimental conduct of biological assays will continue to increase the scope of biological questions that can be explored. Innovations in the synthesis of the polymer microarrays will further increase the combinatorial space that can be investigated, which will, in turn, continue to provide insightful and solutions to the vast array of biomedical problems which involve synthetic materials.

\section{Acknowledgements}

Financial support from the Wellcome Trust is kindly acknowledged (085246).

\section{References}

[1] Webster DC. Combinatorial and high-throughput methods in macromolecular materials research and development. Macromolecular Chemistry and Physics 2008;209(3):237-246.

[2] Lowe G. Combinatorial chemistry. Chemical Society Reviews 1995;24(5):309-\&.

[3] Kohn J, Welsh WJ, Knight D. A new approach to the rationale discovery of polymeric biomaterials. Biomaterials 2007;28(29):4171-4177.

[4] Barber ZH, Blamire MG. High throughput thin film materials science. Materials Science and Technology 2008;24(7):757-770.

[5] Portal C, Bradley M. Approaches to high throughput physical organic chemistry. Organic \& Biomolecular Chemistry 2007;5(4):587-592.

[6] Meier MAR, Schubert US. Combinatorial polymer research and high-throughput experimentation: powerful tools for the discovery and evaluation of new materials. Journal of Materials Chemistry 2004;14(22):3289-3299. 
[7] Xiang XD, Sun XD, Briceno G, Lou YL, Wang KA, Chang HY, Wallacefreedman WG, Chen SW, Schultz PG. A combinatorial approach to materials discovery. Science 1995;268(5218):1738-1740.

[8] Wang JS, Yoo Y, Gao C, Takeuchi I, Sun XD, Chang HY, Xiang XD, Schultz PG. Identification of a blue photoluminescent composite material from a combinatorial library. Science 1998;279(5357):1712-1714.

[9] Tekin E, de Gans BJ, Schubert US. Ink-jet printing of polymers - from single dots to thin film libraries. Journal of Materials Chemistry 2004;14(17):2627-2632.

[10] Chen B, Cui TH, Liu Y, Varahramyan K. All-polymer RC filter circuits fabricated with inkjet printing technology. Solid-State Electronics 2003;47(5):841-847.

[11] Sirringhaus H, Kawase T, Friend RH, Shimoda T, Inbasekaran M, Wu W, Woo EP. High-resolution inkjet printing of all-polymer transistor circuits. Science 2000;290(5499):2123-2126.

[12] Reddington E, Sapienza A, Gurau B, Viswanathan R, Sarangapani S, Smotkin ES, Mallouk TE. Combinatorial electrochemistry: A highly parallel, optical screening method for discovery of better electrocatalysts. Science 1998;280(5370):1735-1737.

[13] Huber J, Amgoune A, Mecking S. Patterning of polymers on a substrate via ink-jet printing of a coordination polymerization catalyst. Advanced Materials 2008;20(10):1978-+.

[14] Kamyshny A, Ben-Moshe M, Aviezer S, Magdassi S. Ink-jet printing of metallic nanoparticles and microemulsions. Macromolecular Rapid Communications 2005;26(4):281-288.

[15] Perelaer J, de Gans BJ, Schubert US. Ink-jet printing and microwave sintering of conductive silver tracks. Advanced Materials 2006;18(16):2101-+.

[16] Mott M, Song JH, Evans JRG. Microengineering of ceramics by direct ink-Jet printing. Journal of the American Ceramic Society 1999;82(7):1653-1658.

[17] Wang J, Mohebi MM, Evans JRG. Two methods to generate multiple compositions in combinatorial ink-jet printing of ceramics. Macromolecular Rapid Communications 2005;26(4):304-309.

[18] Zhao X, Evans JRG, Edirisinghe MJ, Song JH. Ink-jet printing of ceramic pillar arrays. Journal of Materials Science 2002;37(10):1987-1992.

[19] Cull TR, Goulding MJ, Bradley M. Liquid crystal libraries-ink-jet formulation and high-throughput analysis. Advanced Materials 2007;19(17):2355-+.

[20] Kohn J. New approaches to biomaterials design. Nature Materials 2004;3(11):745-747.

[21] Hanak JJ. Multiple-sample-concept in materials research - synthesis, compositonal analysis and testing of entire mulicomponent systems. Journal of Materials Chemistry 1970;5(11):964.

[22] Morgenthaler S, Zink C, Spencer ND. Surface-chemical and -morphological gradients. Soft Matter 2008;4(3):419-434.

[23] Alexander MR, Whittle JD, Barton D, Short RD. Plasma polymer chemical gradients for evaluation of surface reactivity: epoxide reaction with carboxylic acid surface groups. Journal Of Materials Chemistry 2004;14(3):408-412.

[24] Whittle JD, Barton D, Alexander MR, Short RD. A method for the deposition of controllable chemical gradients. Chemical Communications 2003(14):1766-1767.

[25] Meredith JC. Advances in combinatorial and high-throughput screening of biofunctional polymers for gene delivery, tissue engineering and anti-fouling coatings. Journal of Materials Chemistry 2009;19(1):34-45.

[26] Zelzer M, Majani R, Bradley JW, Rose F, Davies MC, Alexander MR. Investigation of cell-surface interactions using chemical gradients formed from plasma polymers. Biomaterials 2008;29(2):172184.

[27] Yang J, Rose FRAJ, Gadegaard N, Alexander MR. A high-throughput assay of cell-surface interactions using topographical and chemical gradients. Advanced Materials 2009;21(3):300-304.

[28] Yliperttula M, Chung BG, Navaladi A, Manbachi A, Urtti A. High-throughput screening of cell responses to biomaterials. European Journal of Pharmaceutical Sciences 2008;35(3):151-160.

[29] Diaz-Mochon JJ, Tourniaire G, Bradley M. Microarray platforms for enzymatic and cell-based assays. Chemical Society Reviews 2007;36(3):449-457. 
[30] Heller MJ. DNA microarray technology: Devices, systems, and applications. Annual Review of Biomedical Engineering 2002;4:129-153.

[31] Venkatasubbarao S. Microarrays - status and prospects Trends in Biotechnology 2004;22(12):630637.

[32] Lee BH, Nagamune T. Protein microarrays and their applications. Biotechnology and Bioprocess Engineering 2004;9(2):69-75.

[33] Hook AL, Voelcker N, Thissen H. Patterned and switchable surfaces for biomolecular manipulation. Acta Biomaterialia 2009;Article In Press:doi:10.1016/j.actbio.2009.1003.1040.

[34] Bretagnol F, Valsesia A, Ceccone G, Colpo P, Gilliland D, Ceriotti L, Hasiwa M, Rossi F. Surface functionalization and pPatterning techniques to design interfaces for biomedical and biosensor applications. Plasma Processes and Polymers 2006;3(6-7):443-455.

[35] Geetha M, Singh AK, Asokamani R, Gogia AK. Ti based biomaterials, the ultimate choice for orthopaedic implants - A review. Progress in Materials Science 2009;54(3):397-425.

[36] Yu LMY, Leipzig ND, Shoichet MS. Promoting neuron adhesion and growth. Materials Today 2008;11(5):36-43.

[37] Vasita R, Shanmugam K, Katti DS. Improved biomaterials for tissue engineering applications: Surface modification of polymers. Current Topics in Medicinal Chemistry 2008;8(4):341-353.

[38] Kim MS, Khang G, Lee HB. Gradient polymer surfaces for biomedical applications. Progress in Polymer Science 2008;33(1):138-164.

[39] Ma ZW, Mao ZW, Gao CY. Surface modification and property analysis of biomedical polymers used for tissue engineering. Colloids and Surfaces B-Biointerfaces 2007;60(2):137-157.

[40] Jiao YP, Cui FZ. Surface modification of polyester biomaterials for tissue engineering. Biomedical Materials 2007;2(4):R24-R37.

[41] Ariga K, Nakanishi T, Michinobu T. Immobilization of biomaterials to nano-assembled films (selfassembled monolayers, Langmuir-Blodgett films, and layer-by-layer assemblies) and their related functions. Journal of Nanoscience and Nanotechnology 2006;6(8):2278-2301.

[42] Shin H, Jo S, Mikos AG. Biomimetic materials for tissue engineering. Biomaterials 2003;24(24):4353-4364.

[43] Poncin-Epaillard F, Legeay G. Surface engineering of biomaterials with plasma techniques. Journal of Biomaterials Science-Polymer Edition 2003;14(10):1005-1028.

[44] Lee CH, Singla A, Lee Y. Biomedical applications of collagen. International Journal of Pharmaceutics 2001;221(1-2):1-22.

[45] Chan CM, Ko TM, Hiraoka H. Polymer surface modification by plasmas and photons. Surface Science Reports 1996;24(1-2):3-54.

[46] Falconnet D, Csucs G, Grandin HM, Textor M. Surface engineering approaches to micropattern surfaces for cell-based assays. Biomaterials 2006;27(16):3044-3063.

[47] Brocchini S, James K, Tangpasuthadol V, Kohn J. Structure-property correlations in a combinatorial library of degradable biomaterials. Journal of Biomedical Materials Research 1998;42(1):66-75.

[48] Anderson DG, Levenberg S, Langer R. Nanoliter-scale synthesis of arrayed biomaterials and application to human embryonic stem cells. Nature Biotechnology 2004;22(7):863-866.

[49] Anderson DG, Putnam D, Lavik EB, Mahmood TA, Langer R. Biomaterial microarrays: rapid, microscale screening of polymer-cell interaction. Biomaterials 2005;26(23):4892-4897.

[50] Tourniaire G, Collins J, Campbell S, Mizomoto H, Ogawa S, Thaburet JF, Bradley M. Polymer microarrays for cellular adhesion. Chemical Communications 2006(20):2118-2120.

[51] Kingshott P, Thissen H, Griesser HJ. Effects of cloud-point grafting, chain length, and density of PEG layers on competitive adsorption of ocular proteins Biomaterials 2002;23(9):2043-2056.

[52] Hook AL, Thissen H, Hayes JP, Voelcker NH. Spatially controlled electro-stimulated DNA adsorption and desorption for biochip applications. Biosensors and Bioelectronics 2005;21(11):21372145. 
[53] Kurkuri MD, Driever C, Johnson G, McFarland G, Thissen H, Voelcker NH. Multifunctional polymer coatings for cell microarray applications. Biomacromolecules 2009;Article ASAP(DOI: 10.1021/bm801417s).

[54] Yasuda H. Plasma Polymerization. Orlando, Florida: Academic Press, 1985.

[55] Mei Y, Gerecht S, Taylor M, Urquhart AJ, Bogatyrev SR, Cho S, Davies MC, Alexander MR, Langer RS, Anderson DG. Mapping the interaction among biomaterials, adsorbed proteins, and human embryonic stem cells. Advanced Materials 2009;21(early view):DOI: 10.1002/adma.200803184.

[56] Thissen H, Johnson G, McFarland G, Verbiest BCH, Gengenbach TR, Voelcker N. Microarrays for the evaluation of cell-biomaterial surface interactions. Proceedings of SPIE 2006;6413:64130B 64131-64139.

[57] Pardo L, Wilson WC, Boland TJ. Characterization of patterned self-assembled monolayers and protein arrays generated by the ink-jet method. Langmuir 2003;19(5):1462-1466.

[58] Zhang R, Liberski A, Khan F, Diaz-Mochon JJ, Bradley M. Inkjet fabrication of hydrogel microarrays using in situ nanolitre-scale polymerisation. Chemical Communications 2008(11):13171319.

[59] Taylor M, Urquhart AJ, Zelzer M, Davies MC, Alexander MR. Picoliter water contact angle measurement on polymers. Langmuir 2007;23(13):6875-6878.

[60] Deegan RD, Bakajin O, Dupont TF, Huber G, Nagel SR, Witten TA. Capillary flow as the cause of ring stains from dried liquid drops. Nature 1997;389(6653):827-829.

[61] Liberski A, Zhang R, Bradley M. Inkjet fabrication of polymer microarrays and grids-solving the evaporation problem. Chemical Communications 2009(3):334-336.

[62] Hook AL, Thissen H, Voelcker NH. Advanced substrate fabrication for cell microarrays. Biomacromolecules 2009;10(3):573-579.

[63] Henry OYF, Piletsky SA, Cullen DC. Fabrication of molecularly imprinted polymer microarray on a chip by mid-infrared laser pulse initiated polymerisation. Biosensors \& Bioelectronics 2008;23(12):1769-1775.

[64] Urquhart AJ, Anderson DG, Taylor M, Alexander MR, Langer R, Davies MC. High throughput surface characterisation of a combinatorial material library. Advanced Materials 2007;19(18):24862491.

[65] Urquhart AJ, Alexander MR. Characterisation using XPS and SIMS. In: Boccaccini AR, Gough JE, editors. Tissue engineering using ceramics and polymers. Cambridge, England: Woodhrad Publishing Limited, 2007. p. 175-203.

[66] Taylor M, Urquhart AJ, Anderson DG, Langer R, Davies MC, Alexander MR. Partial least squares regression as a powerful tool for investigating large combinatorial polymer libraries. Surface and Interface Analysis 2009;41(2):127-135.

[67] Rawsterne RE, Todd SJ, Gough JE, Farrar D, Rutten FJM, Alexander MR, Ulijn RV. Cell spreading correlates with calculated $\log \mathrm{P}$ of amino acid-modified surfaces. Acta Biomaterialia 2007;3(5):715721.

[68] Urquhart AJ, Taylor M, Anderson DG, Langer R, Davies MC, Alexander MR. TOF-SIMS analysis of a 576 micropatterned copolymer array to reveal surface moieties that control wettability. Analytical Chemistry 2008;80(1):135-142.

[69] Engler AJ, Sen S, Sweeney HL, Discher DE. Matrix elasticity directs stem cell lineage specification. Cell 2006;126(4):677-689.

[70] Levin IW, Bhargava R. Fourier transform infrared vibrational spectroscopic imaging: Integrating microscopy and molecular recognition. Annual Review of Physical Chemistry 2005;56:429-474.

[71] Treado PJ, Morris MD. Infrared and raman-spectroscopic imaging. Applied Spectroscopy Reviews 1994;29(1):1-38.

[72] Tweedie CA, Anderson DG, Langer R, Van Vliet KJ. Combinatorial material mechanics: Highthroughput polymer synthesis and nanomechanical screening. Advanced Materials 2005;17(21):2599-+. 
[73] Kumar A, Goel G, Fehrenbach E, Puniya AK, Singh K. Microarrays: The technology, analysis and application. Engineering in Life Sciences 2005;5(3):215-222.

[74] Conrad C, Erfle H, Warnat P, Daigle N, Lorch T, Ellenberg J, Pepperkok R, Eils R. Automatic identification of subcellular phenotypes on human cell arrays. Genome Research 2004;14(6):11301136.

[75] Green RJ, Frazier RA, Shakesheff KM, Davies MC, Roberts CJ, Tendler SJB. Surface plasmon resonance analysis of dynamic biological interactions with biomaterials. Biomaterials 2000;21(18):1823-1835.

[76] Brockman JM, Nelson BP, Corn RM. Surface plasmon resonance imaging measurements of ultrathin organic films. Annual Review of Physical Chemistry 2000;51:41-63.

[77] Rothenhausler B, Knoll W. Surface-Plasmon Microscopy. Nature 1988;332(6165):615-617.

[78] Yeatman E, Ash EA. Surface-plasmon microscopy. Electronics Letters 1987;23(20):1091-1092.

[79] Hook AL, Thissen H, Voelcker NH. Surface plasmon resonance imaging of polymer microarrays to study protein-polymer interactions in high throughput. Langmuir 2009;25(16):9173-9181.

[80] Sorrell CD, Lyon LA. Bimodal swelling responses in microgel thin films. Journal of Physical Chemistry B 2007;111(16):4060-4066.

[81] Yang F, Mei Y, Langer R, Anderson DG. High throughput optimization of stem cell microenvironments. Combinatorial Chemistry and High Throughput Screening 2009;12(6):554-561.

[82] Pernagallo S, Unciti-Broceta A, Diaz-Mochon JJ, Bradley M. Deciphering cellular morphology and biocompatibility using polymer microarrays. Biomedical Materials 2008;3(3).

[83] Pernagallo S, Diaz-Mochon JJ, Bradley M. A cooperative polymer-DNA microarray approach to biomaterial investigation. Lab on a Chip 2009;9(3):397-403.

[84] Mant A, Tourniaire G, Diaz-Mochon JJ, Elliott TJ, Williams AP, Bradley M. Polymer microarrays: Identification of substrates for phagocytosis assays. Biomaterials 2006;27(30):5299-5306.

[85] Tare RS, Khan F, Tourniaire G, Morgan SM, Bradley M, Oreffo ROC. A microarray approach to the identification of polyurethanes for the isolation of human skeletal progenitor cells and augmentation of skeletal cell growth. Biomaterials 2009;30(6):1045-1055.

[86] Vroman L. Effect of Adsorbed Proteins on the Wettability of Hydrophilic and Hydrophobic Solids. Nature 1962;196(4853):476-477.

[87] Taylor M, Urquhart AJ, Anderson DG, Williams PM, Langer R, Alexander MR, Davies MC. A methodology for investigating protein adhesion and adsorption to microarrayed combinatorial polymers. Macromolecular Rapid Communications 2008;29(15):1298-1302.

[88] Flaim CJ, Chien S, Bhatia SN. An extracellular matrix microarray for probing cellular differentiation. Nature Methods 2005;2(2):119-125.

[89] Ziauddin J, Sabatini DM. Microarrays of cells expressing defined cDNAs Nature 2001;411(6833):107-110.

[90] Hook AL, Voelcker N, Thissen H. Surface manipulation of biomolecules for cell microarray applications. Trends in Biotechnology 2006;24(10):471-477.

[91] Delehanty JB, Shaffer KM, Lin BC. A comparison of microscope slide substrates for use in transfected cell microarrays Biosensors and Bioelectronics 2004;20(4):773-779.

[92] Unciti-Broceta A, Diaz-Mochon JJ, Mizomoto H, Bradley M. Combining nebulization-mediated transfection and polymer microarrays for the rapid determination of optimal transfection substrates. Journal of Combinatorial Chemistry 2008;10(2):179-184.

[93] Yang J, Mei Y, Bogatyrev SR, Taylor M, Urquhart AJ, Anderson DG, Langer R, Davies MC, Alexander MR. Predicting human embryonic stem cell attachment to the surface of acrulate polymers synthesised as a microarray using ion spectometry. Biomaterials 2009; In press. 


\section{Tables}

Table 1. Description of key advances in biomaterial microarray technology, in chronological order.

\begin{tabular}{|c|c|c|c|}
\hline Description & Materials & Significance & Reference \\
\hline $\begin{array}{l}\text { Formation of a combinatorial } \\
\text { library of ceramic materials in an } \\
\text { array format }\end{array}$ & $\begin{array}{l}\text { Mineral array, } 128 \text { types } \\
\text { derived from combinations of } \\
5 \text { materials }\end{array}$ & $\begin{array}{l}\text { First demonstration of a microarray } \\
\text { of materials }\end{array}$ & $\begin{array}{l}\text { Xiang et al., } \\
(1995) \text { [7] }\end{array}$ \\
\hline $\begin{array}{l}\text { Study of the proliferation of } \\
\text { fibroblasts on a combinatorial } \\
\text { library of polymers }\end{array}$ & $\begin{array}{l}\text { Degradable polyarylates, } 42 \\
\text { co-polymers derived from } 6 \\
\text { diphenol monomers and } 7 \\
\text { diacid monomers. }\end{array}$ & $\begin{array}{l}\text { First demonstration of screening a } \\
\text { combinatorial library of polymers for } \\
\text { biological performance as an } \\
\text { approach to biomaterials design. }\end{array}$ & $\begin{array}{l}\text { Brocchini et al., } \\
\text { (1998) [47] }\end{array}$ \\
\hline $\begin{array}{l}\text { Study of stem cell attachment and } \\
\text { differentiation on a polymeric } \\
\text { library }\end{array}$ & $\begin{array}{l}\text { Polyacrylates, } 576 \text { member } \\
\text { library (in triplicate) created } \\
\text { from } 24 \text { monomers, } \\
\text { polymerised on the glass } \\
\text { slide }\end{array}$ & $\begin{array}{l}\text { First production of a microarray of } \\
\text { polymers for screening cell response. } \\
\text { First demonstration of on-chip } \\
\text { polymerisation. First use of pHEMA } \\
\text { as a slide coating. }\end{array}$ & $\begin{array}{l}\text { Anderson et al., } \\
\text { (2004) [48] }\end{array}$ \\
\hline $\begin{array}{l}\text { Study of stem cells attachment to } \\
\text { biodegradable polymers }\end{array}$ & $\begin{array}{l}\text { Polyesters, } 1152 \text { polymer } \\
\text { blends from } 24 \text { pre- } \\
\text { synthesised polymers }\end{array}$ & $\begin{array}{l}\text { First demonstration of printing pre- } \\
\text { synthesised polymers for formation } \\
\text { of a materials microarray }\end{array}$ & $\begin{array}{l}\text { Anderson et al., } \\
(2005)[49]\end{array}$ \\
\hline $\begin{array}{l}\text { Investigation of the mechanical } \\
\text { properties of polymers by } \\
\text { nanoidentation }\end{array}$ & $\begin{array}{l}\text { Polyacrylates, } 576 \text { member } \\
\text { library (in triplicate) created } \\
\text { from } 24 \text { monomers, } \\
\text { polymerised on the glass } \\
\text { slide }\end{array}$ & $\begin{array}{l}\text { First demonstration of measurements } \\
\text { of the elastic modulus of materials in } \\
\text { a high throughput manner }\end{array}$ & $\begin{array}{l}\text { Tweedie et al., } \\
\text { (2005) [72] }\end{array}$ \\
\hline $\begin{array}{l}\text { Study of human renal tubular cells } \\
\text { attachment to polymers }\end{array}$ & $\begin{array}{l}\text { Polyurethanes, } 210 \text { member } \\
\text { library of pre-synthesised } \\
\text { polymers created from } 20 \\
\text { monomers }\end{array}$ & $\begin{array}{l}\text { First demonstration of agarose as a } \\
\text { slide coating. Early example of } \\
\text { printing pre-synthesised polymers for } \\
\text { formation of a materials micoarray. }\end{array}$ & $\begin{array}{l}\text { Tourniaire et } \\
\text { al., (2006) [50] }\end{array}$ \\
\hline $\begin{array}{l}\text { Study of the chemistry and } \\
\text { wettability of a polymer microarray } \\
\text { in high throughput }\end{array}$ & $\begin{array}{l}\text { Polyacrylates, } 576 \text { member } \\
\text { library created from } 24 \\
\text { monomers, polymerised on } \\
\text { the glass slide }\end{array}$ & $\begin{array}{l}\text { First demonstration of the ability to } \\
\text { characterise a polymer microarray in } \\
\text { a high throughput manner }\end{array}$ & $\begin{array}{l}\text { Urquhart et al., } \\
\text { (2007) [64] }\end{array}$ \\
\hline $\begin{array}{l}\text { Study identifying the surface } \\
\text { functionalities of acrylate polymers } \\
\text { controlling wettability }\end{array}$ & $\begin{array}{l}\text { Polyacrylates, } 576 \text { member } \\
\text { library created from } 24 \\
\text { monomers, polymerised on } \\
\text { the glass slide }\end{array}$ & $\begin{array}{l}\text { First demonstration of the ability of } \\
\text { PLS to correlate a univariate property } \\
\text { with multivariate ToF-SIMS data. } \\
\text { Demonstration of the ability to } \\
\text { predict wettability from chemical } \\
\text { functionality. }\end{array}$ & $\begin{array}{l}\text { Urquhart et al., } \\
\text { (2008) [68] }\end{array}$ \\
\hline Formation of a hydrogel microarray & $\begin{array}{l}\text { Polyacrylates and } \\
\text { polyacrylamides, } 37 \text { member } \\
\text { library containing both pre- } \\
\text { synthesised and on-chip } \\
\text { polymerised polymers }\end{array}$ & $\begin{array}{l}\text { First printing of monomers in an } \\
\text { array format by ink-jet printing. } \\
\text { Demonstration of the possibility of } \\
\text { on-chip mixing of monomers. }\end{array}$ & $\begin{array}{l}\text { Zhang et al., } \\
(2008) \text { [58] }\end{array}$ \\
\hline $\begin{array}{l}\text { Assessment of the specific } \\
\text { attachment of human } \\
\text { progenior cells with a materials } \\
\text { microarray }\end{array}$ & $\begin{array}{l}\text { Polyurethanes, } 120 \text { member } \\
\text { library }\end{array}$ & $\begin{array}{l}\text { Demonstration of the ability to use } \\
\text { microarrays to identify materials that } \\
\text { can be used to isolate specific } \\
\text { osteoblast-like cell lines from a bone } \\
\text { marrow population }\end{array}$ & $\begin{array}{l}\text { Tare et al., } \\
(2009)[84]\end{array}$ \\
\hline $\begin{array}{l}\text { Study the interaction of HeLa cells } \\
\text { with various biomolecules, } \\
\text { synthetic and natural polymers }\end{array}$ & $\begin{array}{l}\text { Proteins, synthetic and } \\
\text { natural polymers, } 12 \text { member } \\
\text { library }\end{array}$ & $\begin{array}{l}\text { Demonstration of a low-fouling PEG } \\
\text { coating that can covalently link any } \\
\text { deposited molecule to the surface }\end{array}$ & $\begin{array}{l}\text { Kurkuri et al., } \\
(2009)[53]\end{array}$ \\
\hline $\begin{array}{l}\text { Study of the interaction of pre- } \\
\text { adsorbed Fn and embroid-body } \\
\text { stem cells with a material array }\end{array}$ & $\begin{array}{l}\text { Polyacrylates, } 496 \text { member } \\
\text { library created from } 22 \\
\text { monomers, polymerised on } \\
\text { the glass slide }\end{array}$ & $\begin{array}{l}\text { Demonstrated the ability to correlate } \\
\text { cell attachment with a conditioning } \\
\text { protein layer and the surface } \\
\text { chemistry }\end{array}$ & $\begin{array}{l}\text { Mei et al., } \\
(2009)[55]\end{array}$ \\
\hline
\end{tabular}




\section{Figure Headings}

Figure 1. Schematic of the formation of an array of materials by a sequential sputtering and masking procedure. Initially, a mask is applied to a surface and a material is sputtered onto the uncovered regions on the substrate. The mask is then shifted or exchanged and a new material is sputtered onto the surface. This process can be repeated with many different materials to produce a large combinatorial library of materials. Based upon the technique described in reference [7].

Figure 2. Schematic of the formation of a materials microarray using contact or ink-jet printing. Spotted solution, shown as red, are transferred from a multi-well source plate to a substrate. The solid or quilled pins used for contact printing or the nozzle used for ink-jet printing are depicted.

Figure 3. a) Schematic of the formation of a materials microarray by depositing monomers and initiating the in situ polymerisation. The process involves four steps; the printing of a monomer solution containing initiator, the irradiation with UV to activate the initiator, the polymerisation of the monomer, and the vacuum extraction of the solvent. Polymer is shown as red. Based upon the technique described in reference [48]. b) An image of a typical polymer microarray formed by this approach.

Figure 4. Schematic of the experimental setup for the formation of a materials microarray by laser initiated polymerisation. Based upon the technique described in reference [63].

Figure 5. Schematic depiction of the toolbox of techniques that can be applied to HTSA. Schematic not to scale.

Figure 6. hES cells grown on polymer arrays. (a-c) Six million human ES cell embryoid body day-6 cells were added on the polymer array in the presence of retinoic acid for 6 day and then stained for cytokeratin 7 (green) and vimentin (red). Polymer spots can be identified by blue fluorescence. (d) Nuclei were also stained (green) (not shown in other images to simplify presentation). (e) Typical cytokeratin 7 positive spot. From reference [48] with permission.

Figure 7. (a) Map of the relationship between cell attachment and polymer composition. Cell number per spot was grouped into four catagories $1-29,30-59,60-89$, and 90-119 per spot. Cell numbers are mapped as a function of polymer composition. (b) A map of the relationship between Fn adsorption and polymer composition, the major monomer 5, 6, 7, and 10 are excluded due to autofluorescence from the polymer spots. From reference [55] with permission. 


\section{Figures}

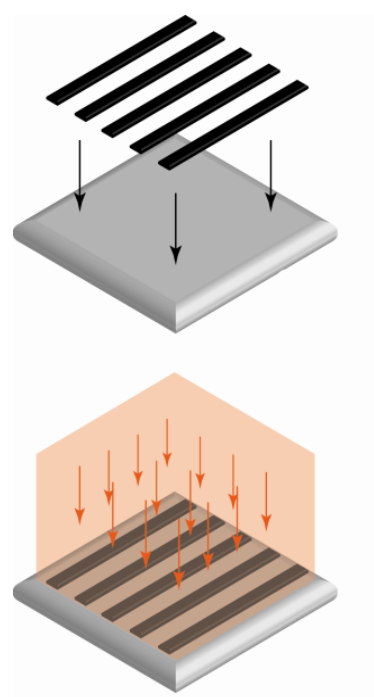

Apply mask to

substrate

Deposit material
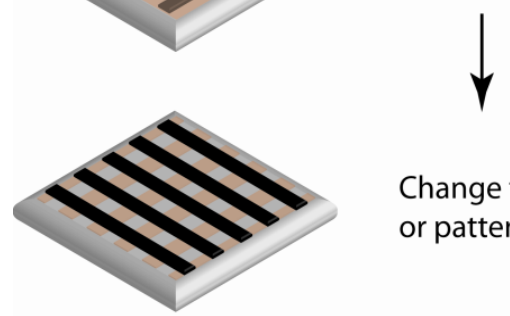

Change the position

or pattern of the mask

$r$
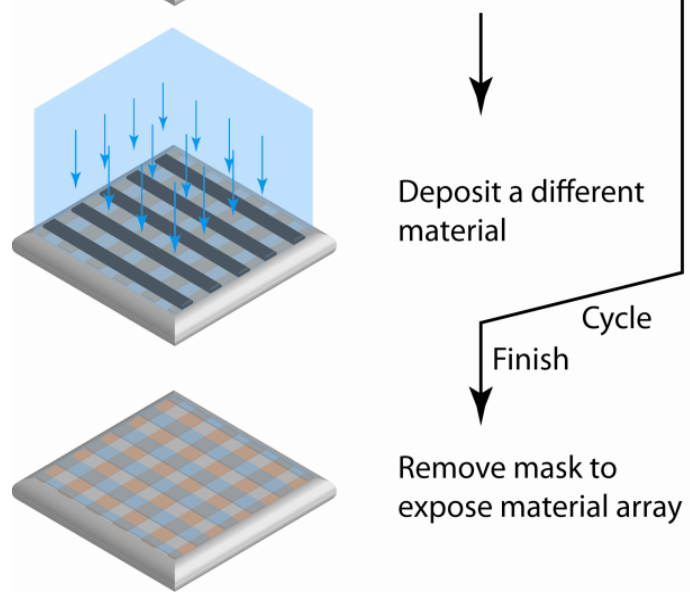

Remove mask to

expose material array

Figure 1 


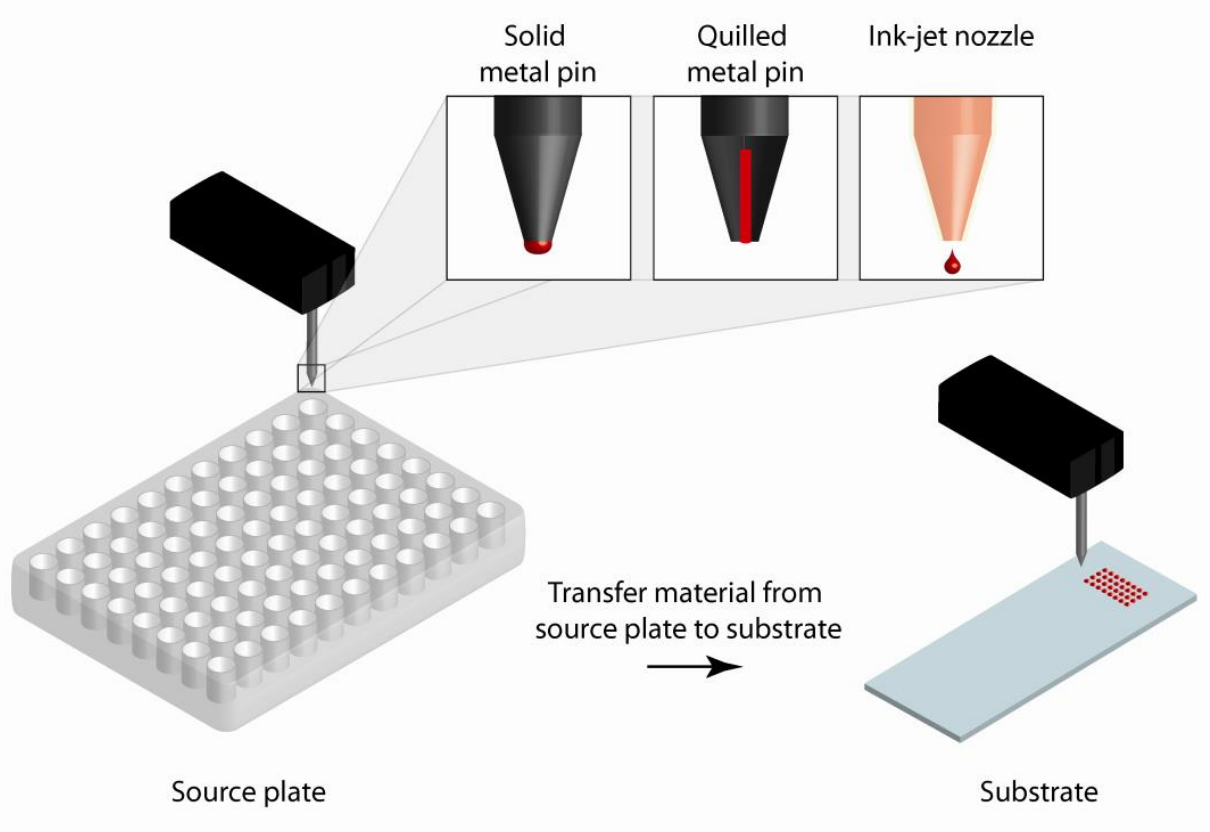

Figure 2

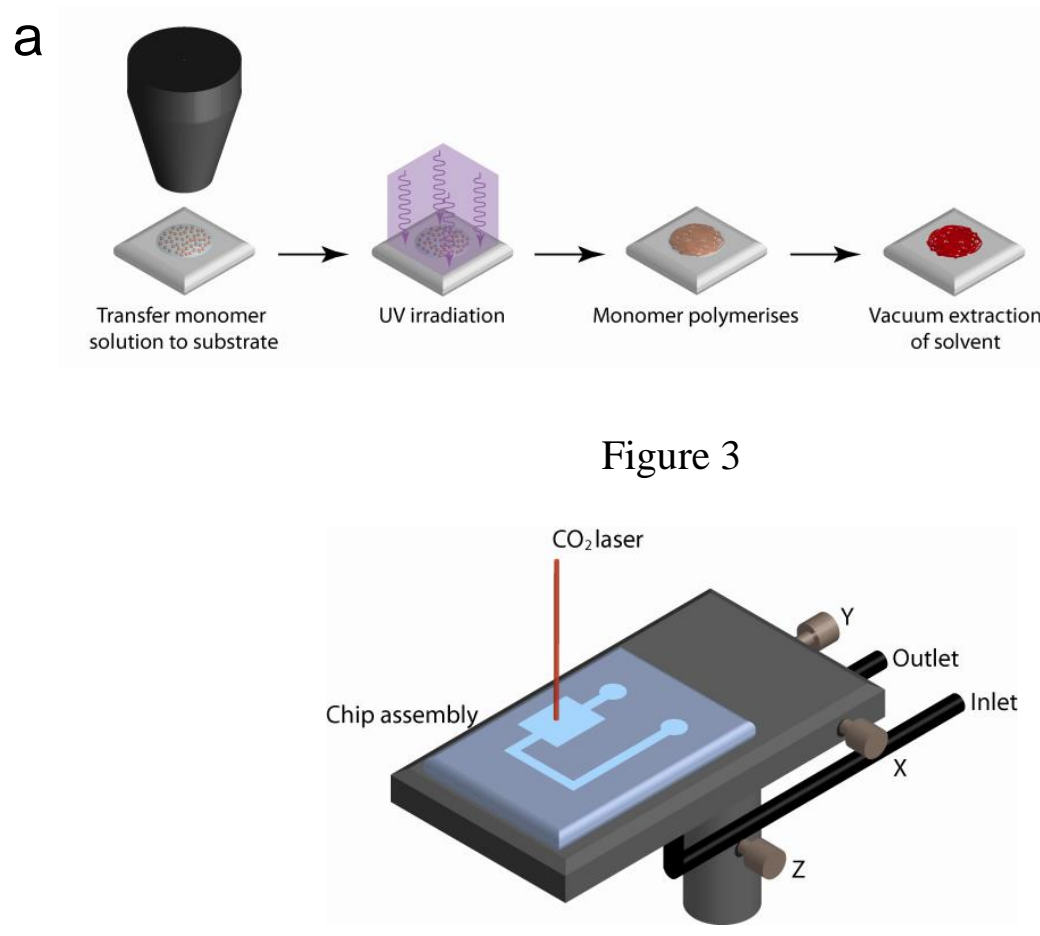

Figure 4 


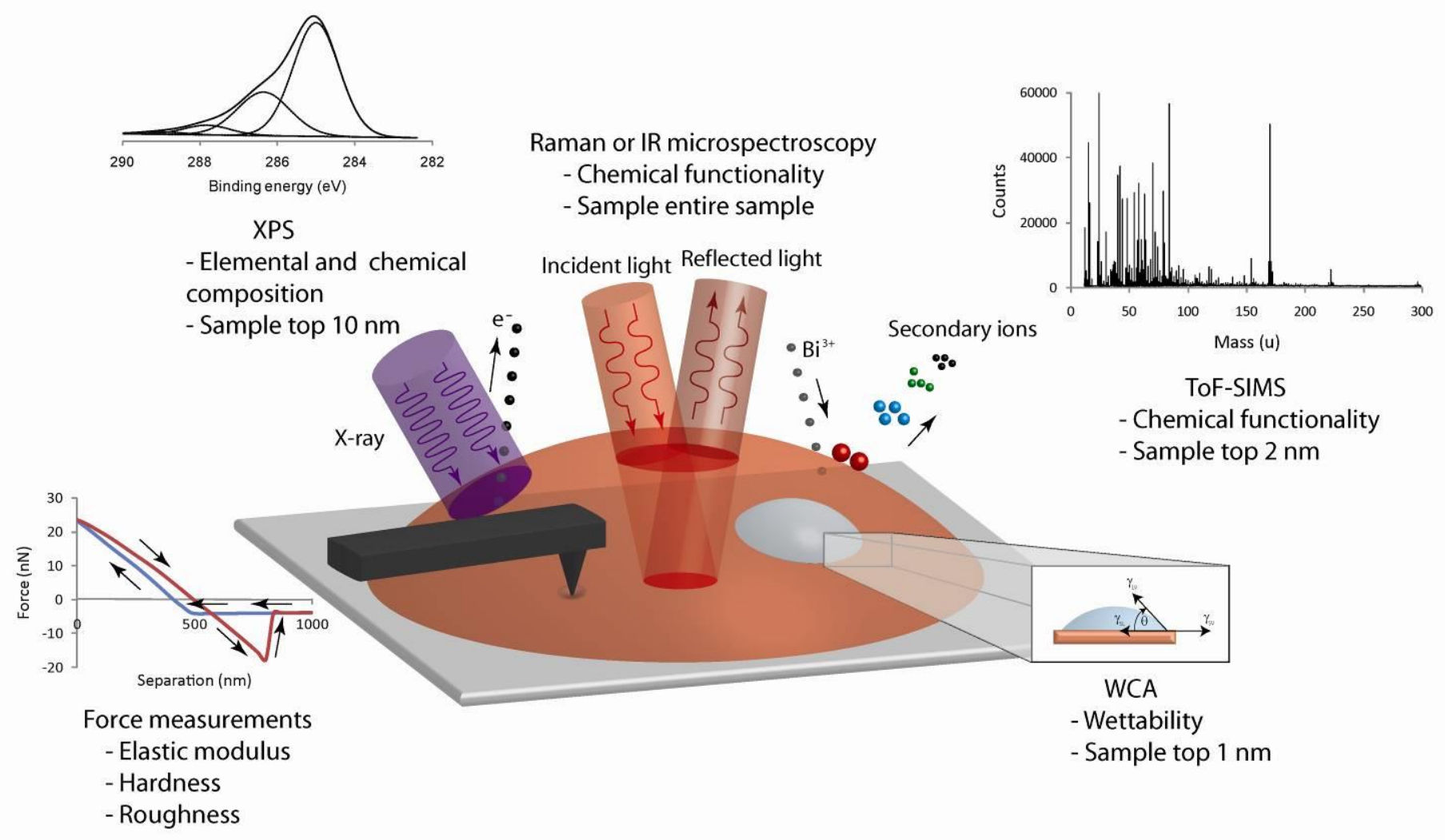

Figure 5
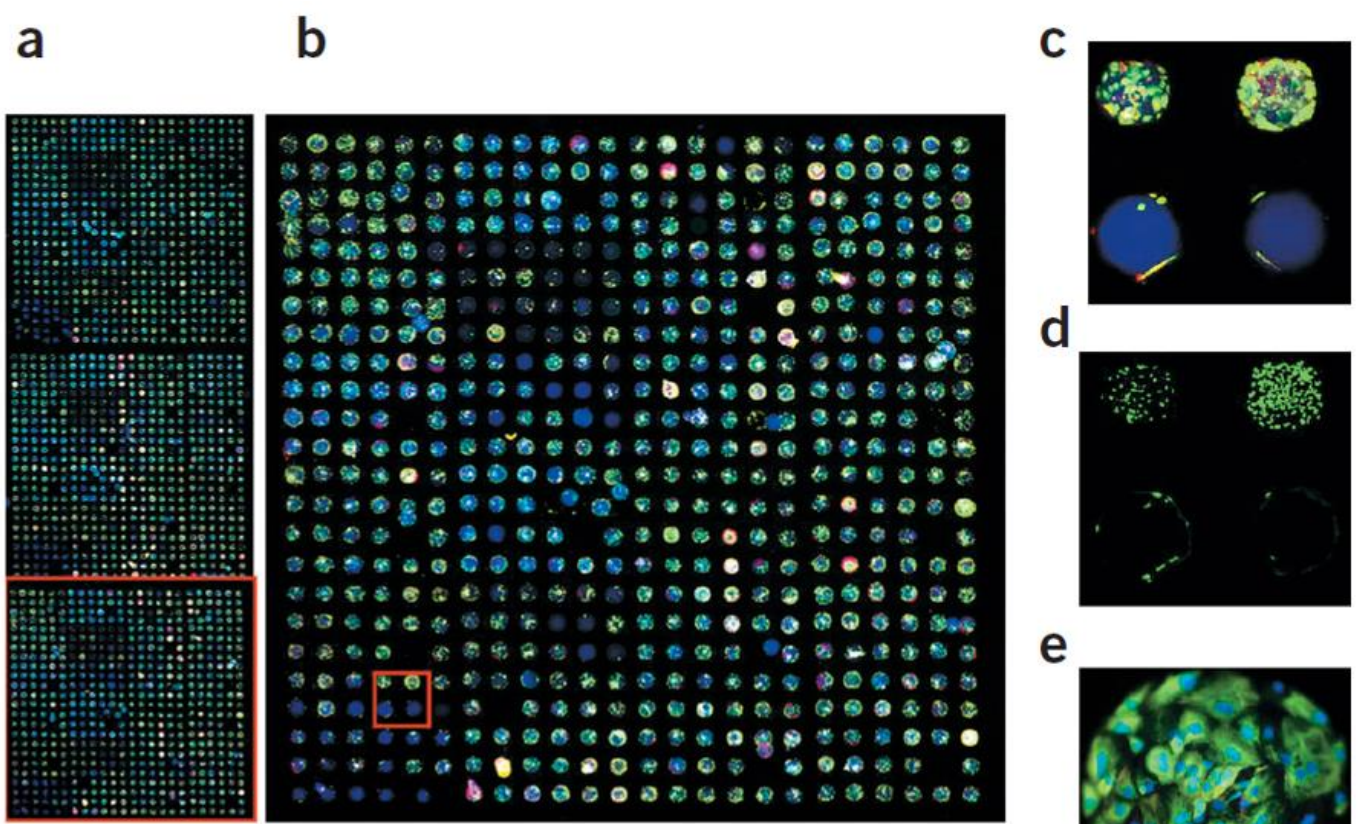

e

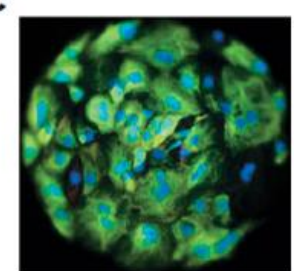

Figure 6 

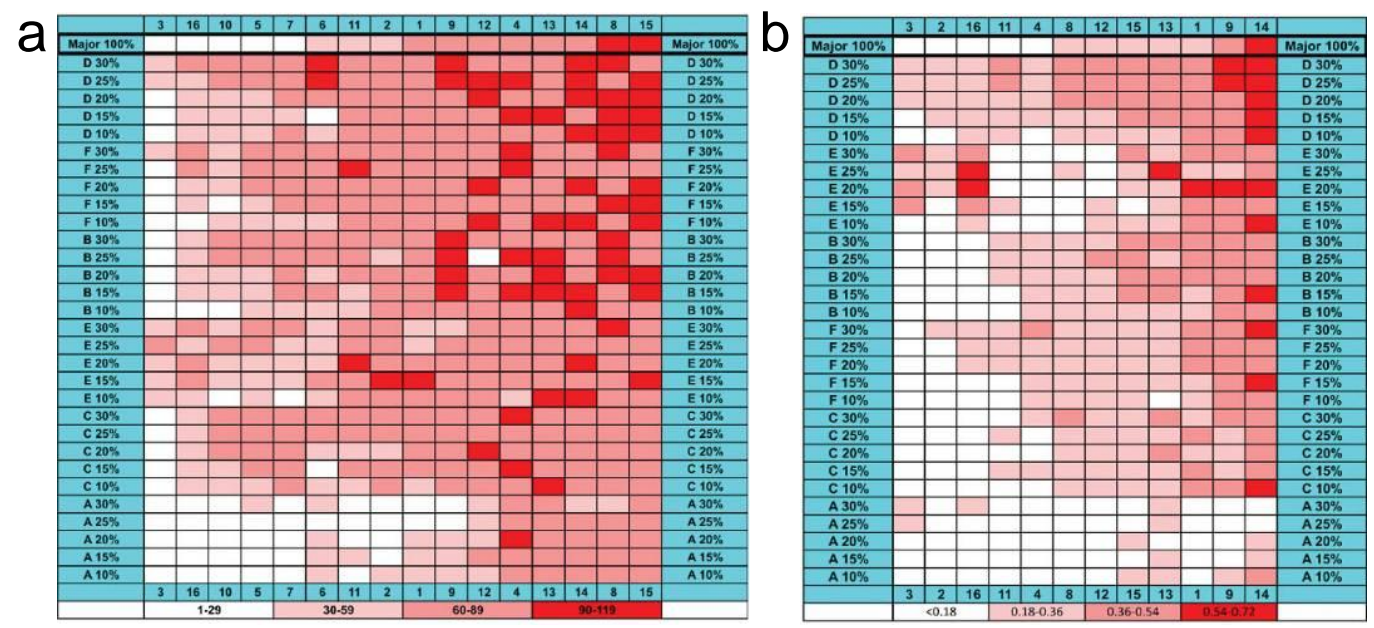

Figure 7 